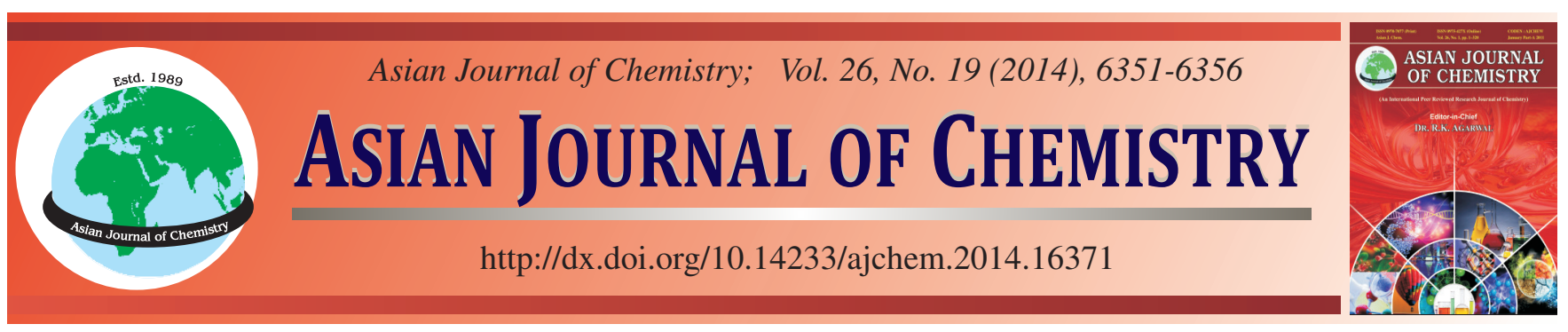

\title{
UHPLC Analysis of Polyphenol Composition and Antioxidant Activity from Different Solvent Extracts of Coriandrum sativum Seeds Cultivated in Korea
}

\author{
Praveen Nagella, Muthu Thiruvengadam, Ateeque Ahmad and Ill-Min Chung*
}

Department of Applied Bioscience, College of Life and Environmental Sciences, Konkuk University, Seoul 143 701, Republic of Korea

*Corresponding author: Fax: +82 2 4467856; Tel: +82 2 4503730; E-mail: imcim@konkuk.ac.kr

Received: 14 September 2013;

Accepted: 17 December 2013;

Published online: 16 September 2014;

AJC-15916

\begin{abstract}
The aim of this work was to establish the polyphenolic profile and antioxidant capacity of Coriandrum sativum seeds that could potentially be used in the human diet. An ultra high performance liquid chromatographic method was used to identify and quantify individual phenolic compounds of the $C$. sativum seeds. A total of 24 polyphenolic compounds were identified and quantified in $C$. sativum seeds, including hydroxybenzoic acids, hydroxycinnamic acids, flavonols and other groups of phenolic compounds. Ultra high performance liquid chromatographic analysis of the seed extract revealed that salicylic acid was the dominant phenolic compound in coriander seed extract, it constituted about $650.80 \mu \mathrm{g} / \mathrm{g}$, followed by gentisic acid $(223.45 \mu \mathrm{g} / \mathrm{g})$, chlorogenic acid $(162.10 \mu \mathrm{g} / \mathrm{g})$, pyrogallol $(138.80 \mu \mathrm{g} /$ $\mathrm{g})$ and syringic acid $(90.95 \mu \mathrm{g} / \mathrm{g}$ ). The $C$. sativum seeds was extracted with 4 different solvents (ethyl acetate, methanol, butanol and water) and screened for total phenolic content, total flavonoid content and antioxidant activity. The antioxidant activity of $C$. sativum seeds was assessed by evaluating the 1,1-diphenyl-2-picrylhydrazyl (DPPH), reducing power, metal chelating and phosphomolybdenum assay. Ethyl acetate extract exhibited the highest phenolic $(23.09 \mathrm{mg} / \mathrm{g}$ gallic acid equivalent) and flavonoid contents $(1.08 \mathrm{mg} / \mathrm{g}$ quercetin equivalent). The ethyl acetate extract possesses highest antioxidant activity towards DPPH, reducing power, metal chelating and phosphomolybdenum assay. The antioxidant activity among the $C$. sativum seed extracts assayed through all the four methods was found to be ethyl acetate $>$ butanol $>$ methanol $>$ water extract. In conclusion, addition of coriander seeds to food increases the antioxidant content and may have potential as a natural antioxidant and thus inhibit undesired oxidation processes.
\end{abstract}

Keywords: Coriandrum sativum, Polyphenolic composition, Antioxidant activity, DPPH activity, Metal chelating activity.

\section{INTRODUCTION}

Coriander (Coriandrum sativum L.) is widely distributed and mainly cultivated for seeds. The seeds contain an essential oil and the monoterpenoid, linalool, is the main component ${ }^{1}$. This culinary and medicinal plant from the Umbelliferae family is of economic importance since it has been used as a flavoring agent in food products, perfumes and cosmetics. Powdered seeds or dry extract, tea, tincture, decoction or infusion have been recommended for dyspeptic complaints, loss of appetite, convulsion, insomnia and anxiety ${ }^{2}$. Moreover, the essential oils and various extracts from coriander have been shown to possess antibacterial, antioxidant, antidiabetic, anticancerous and antimutagenic activities ${ }^{3}$.

In recent years, there has been a trend towards the use of natural phytochemicals present in natural resources like oilseeds, herbs, fruits and vegetables serve as potential antioxidants and functional ingredients ${ }^{4,5}$. Many degenerative human diseases including cancer, cardiovascular and cerebro-vascular diseases have been recognized as being a possible consequence of free radical damage to lipids, proteins and nucleic acids ${ }^{6}$. A possible way to fight these diseases is to improve our body's antioxidant defenses. The functional bioactivity of a plant extract, in general depends upon the presence of compounds such as polyphenols, carotenoids and chlorophyll ${ }^{6}$. Polyphenolic compounds are a group of low and medium molecular weight secondary metabolites that are widely distributed in plants, which can be divided into two major subgroups: flavonoids and phenolic acids. Phenolic acids include mainly hydroxybenzoic acids (e.g. benzoic acid, gentisic acid or $p$-anisic acid) and hydroxycinnamic acids (e.g. caffeic or ferulic acid conjugates, sinapic acid). There is a much higher quantity and diversity of hydroxycinnamates than hydroxybenzoates and they consist of $p$-coumaric acid, caffeic acid, ferulic acid and sinapic acid either glycosylated or esterified with quinic, shikimic or tartaric acids. In fruits and leaves, the main hydroxycinnamates result from the esterification of caffeic acid groups(s) with quinic acid, the most frequent and abundant caffeoylquinic acid isomer being 5-0-caffeoylquinic acid (chlorogenic acid). In cereal grains, ferulic acid esters are the 
most common hydroxycinnamates. Flavonoids, perhaps the most important single group of phenolics in foods, comprise a group of over 4000 aromatic plant compounds. They include anthocyanins, proanthocyanidins, flavonols and catechins ${ }^{7}$. Epidemiological studies have provided evidence of beneficial health effects of dietary fruits and vegetables and the beneficial effects have been attributed at least in part to secondary metabolites, including flavonoids and hydroxycinnamic acids ${ }^{8}$. Phenolic compounds are associated with a high number of biological activities and one with special interest is the antioxidant capacity ${ }^{9}$. Antioxidants are often added to foods to prevent the radical chain reactions of oxidation by inhibiting the initiation and propagation step leading to the termination of the reaction and a delay in the oxidation process.

Different studies have proven that coriander extracts and essential oil exhibit antioxidant activities ${ }^{10-12}$. Although substantial data of the essential oil composition of $C$. sativum is available, but there is no previous reports on the polyphenolic constituents recorded from $C$. sativum $\mathrm{L}$. cultivated in Korea. So, In view of this we aim to investigate the polyphenolic composition and antioxidant activity from different solvent extracts of $C$. sativum seeds grown in Korea. According to the recommendations, the antioxidant effects in more than three different bioassays were studied, besides determination of total phenolics and flavonoids. The study of polyphenolic composition is an important scientific agenda for food and nutritional sciences, which may contribute to the improvement of conventional foods with added health benefits being very useful to determine these chemicals in plants, in the field of nutrition, pharmacology and agronomy. To the best of our knowledge, this is the first report on the polyphenolic composition and antioxidant activity from the seeds of $C$. sativum cultivated in Korea.

\section{EXPERIMENTAL}

The C. sativum seeds were procured from Danong Company, Namyanju-si, Gyeonggi-do, South Korea in October 2011. A voucher specimen is deposited in the Department of Applied Life Sciences, Konkuk University, Seoul, South Korea.

Extraction of phenolic compounds for the ultra high performance liquid chromatography (UHPLC) analysis: One gram of powdered seed material was extracted in $10 \mathrm{~mL}$ of acetonitrile and $2 \mathrm{~mL}$ of $0.1 \mathrm{~N}$ hydrochloric acid. The mixture was stirred for $2 \mathrm{~h}$ at room temperature. The extract was filtered through No. 42 Whatman filter paper and was concentrated using a vacuum evaporator. The residues were dissolved in 10 $\mathrm{mL}$ of $80 \%$ aqueous methanol and filtered through a $0.45 \mu \mathrm{m}$ membrane. The filtrate was used for the UHPLC analysis.

Ultra high performance liquid chromatography analysis of the phenolic compounds: UHPLC was performed using the Thermo Accela UHPLC (Thermo, New York, USA) system. Separation was primarily achieved using a HALO C18 $(2.7 \mu \mathrm{m}, 2.1 \times 100 \mathrm{~mm})$ column and the absorbance were measured at $280 \mathrm{~nm}$. The mobile phases were $0.1 \%$ glacial acetic acid in distilled water (solvent $\mathrm{A}$ ) and $0.1 \%$ glacial acetic acid in acetonitrile (solvent B). The injection volume was $4 \mu \mathrm{L}$ and the linear gradient of UHPLC solvents was as follows: $0 \mathrm{~min}, 92 \mathrm{~A}$ : $8 \% \mathrm{~B}$; 0-2.2 $\mathrm{min}, 90 \mathrm{~A}$ : $10 \% \mathrm{~B} ; 2.2-5$ $\min , 85 \mathrm{~A}: 15 \% \mathrm{~B} ; 5-7.5 \mathrm{~min}, 84.5 \mathrm{~A}: 15.5 \% \mathrm{~B} ; 7.5-8.5$ $\min , 82.2 \mathrm{~A}: 17.8 \% \mathrm{~B} ; 8.5-13 \mathrm{~min}, 55 \mathrm{~A}: 45 \% \mathrm{~B} ; 13-14$ min, $0 \mathrm{~A}: 100 \% \mathrm{~B}$; and $14-15 \mathrm{~min}, 92 \mathrm{~A}: 8 \% \mathrm{~B}$. The run time was $15 \mathrm{~min}$ and the flow rate was $500 \mu \mathrm{L} / \mathrm{min}$.

Solutions of available pure known compounds, gallic acid, pyrogallol, protocatechuic acid, gentisic acid, $\beta$-resorcylic acid, chlorogenic acid, vanillic acid, syringic acid, vanillin, $p$-coumaric acid, salicylic acid, ferulic acid, veratric acid, $m$-coumaric acid, rutin, $o$-coumaric acid, hesperedin, myricetin, resveratrol, quercetin, naringenin, kaempferol, formononetin and biochanin A were chromatographed as external standards. All standards were dissolved in methanol before injections in the analytical UHPLC system. Their ranges of concentration used were $25,50,100,150 \mu \mathrm{g} / \mathrm{mL}$. Phenolic compounds of seed extract were identified by comparing their retention times with those of pure compounds. The results were expressed as $\mu \mathrm{g} / \mathrm{g}$ of each compound from the total phenolic compounds.

Preparation of extracts for total phenolic, flavonoid contents and antioxidant activity: Coriander seeds $(1 \mathrm{~kg})$ were extracted with $4 \times 2 \mathrm{~L}$ dichloromethane at room temperature for $24 \mathrm{~h}$ prior removal of the solvent in vacuo, yielding dichloromethane extract. The residue was further extracted similarly with $5 \times 2 \mathrm{~L}$ methanol for $24 \mathrm{~h}$ and the combined methanol extracts were taken to dryness. The crude methanol extract was suspended in $0.5 \mathrm{~L}$ distilled water and extracted successively with $5 \times 0.5 \mathrm{~L}$ of ethyl acetate and $5 \times 0.5 \mathrm{~L}$ of $n$-butanol. After removal of solvents in vacuo, extracts of ethyl acetate, methanol, butanol and water were obtained, respectively.

Determination of total phenolic content: The total phenolic content was determined by the Folin-Ciocalteu (FC) method $^{13}$. Distilled water $(3.16 \mathrm{~mL})$ was mixed with a DMSO solution of the test compound $(40 \mu \mathrm{L})$. Then, $200 \mu \mathrm{L}$ of FC reagent was added. After $5 \mathrm{~min}, 600 \mu \mathrm{L}$ of $20 \%$ sodium carbonate solution was added and the solutions were mixed again. The solutions were left at room temperature for $2 \mathrm{~h}$. Then the absorption of the developed blue color was determined at 765 $\mathrm{nm}$, using a UV-visible spectrophotometer (Mecasys, Korea). The concentration of the total phenolic content was determined as mg of gallic acid equivalent by using an equation obtained from gallic acid calibration curve. The estimation of phenolic compounds in the fractions was carried out in triplicate and the results were averaged.

Determination of total flavonoid content: Total flavonoid content of coriander seed extracts were determined by using the aluminium chloride colorimetric method ${ }^{14}$, with some modifications. Extracts $(0.5 \mathrm{~mL}), 10 \%$ aluminium chloride $(0.1 \mathrm{~mL}), 1 \mathrm{M}$ potassium acetate $(0.1 \mathrm{~mL})$ and distilled water $(4.3 \mathrm{~mL})$ were mixed. After incubation at room temperature for $0.5 \mathrm{~h}$. The absorbance was measured at $415 \mathrm{~nm}$ using a UV-visible spectrophotometer (Mecasys, Korea). Quercetin was used to make the calibration curve. The estimation of total flavonoids in the extracts was carried out in triplicate and the results were averaged.

DPPH radical scavenging assay: The antioxidant activity of the extracts from coriander seeds, based on the scavenging activity of the stable 1,1-diphenyl-2-picrylhrdrazyl (DPPH') free radical was determined by the method described by Katerere 
and Eloff ${ }^{15}$. Different concentrations ( 25 to $100 \mu \mathrm{g} / \mathrm{mL}$ ) of the extracts were taken in different test tubes with $4 \mathrm{~mL}$ of a 0.006 $\% \mathrm{MeOH}$ solution of $\mathrm{DPPH}^{\circ}$. Water/methanol in place of the extracts was used as control. Absorbance at $517 \mathrm{~nm}$ was determined after 40 min of incubation at room temperature. Radical scavenging activity was expressed as the inhibition percentage and was calculated using the following formula:

$$
\text { Radical scavenging activity }(\%)=\frac{\left(\mathrm{A}_{\text {blank }}-\mathrm{A}_{\text {sample }}\right)}{\mathrm{A}_{\text {blank }}} \times 100
$$

where $A_{\text {blank }}$ is the absorbance of the control at 40 min reaction (containing all reagents except the test compound) and $\mathrm{A}_{\text {sample }}$ is the absorbance of the sample at $40 \mathrm{~min}$.

Assay of reductive potential: The reducing power of the extracts was determined according to the method of Oyaizu ${ }^{16}$. Different extracts of concentration (250 to $1000 \mu \mathrm{g} / \mathrm{mL}$ ) in $1 \mathrm{~mL}$ of distilled water was mixed with $2.5 \mathrm{~mL}$ of $200 \mathrm{mM}$ sodium phosphate buffer ( $\mathrm{pH}$ 6.6) and $2.5 \mathrm{~mL}$ of $1 \%$ potassium ferricyanide and the mixture was incubated at $50{ }^{\circ} \mathrm{C}$ for $20 \mathrm{~min}$. Then, $2.5 \mathrm{~mL}$ of $10 \%$ trichloroacetic acid was added to the mixture and centrifuged at $650 \mathrm{~g}$ for $10 \mathrm{~min}$. The upper layer of the solution $(2.5 \mathrm{~mL})$ was mixed with $2.5 \mathrm{~mL}$ of distilled water and $0.5 \mathrm{~mL}$ of $0.1 \%$ ferric chloride and the absorbance was measured at $700 \mathrm{~nm}$ against a blank. Increased absorbance of the reaction mixture indicated increased reducing power. All analysis were run in triplicate and averaged.

Metal chelating activity: The chelating effect was determined according to the method of Dinis et al. ${ }^{17}$. Briefly, $2 \mathrm{~mL}$ of various concentrations ( 50 to $250 \mu \mathrm{g} / \mathrm{mL}$ ) of the extracts in methanol was added to a solution of $2 \mathrm{mM} \mathrm{FeCl}_{2}(0.05 \mathrm{~mL})$. The reaction was initiated by the addition of $5 \mathrm{mM}$ ferrozine $(0.2 \mathrm{~mL})$. Then, the mixture was shaken vigorously and left at room temperature for $10 \mathrm{~min}$. Absorbance of the solution was measured spectrophotometrically at $562 \mathrm{~nm}$. The inhibition percentage of ferrozine- $\mathrm{Fe}^{2+}$ complex formation was calculated by using the formula given below:

$$
\text { Metal chelating effect }(\%)=\frac{\left(\mathrm{A}_{\text {control }}-\mathrm{A}_{\text {sample }}\right)}{\mathrm{A}_{\text {control }}} \times 100
$$

where $\mathrm{A}_{\text {control }}$ is the absorbance of control (the control contains $\mathrm{FeCl}_{2}$ and ferrozine complex formation molecules) and $\mathrm{A}_{\text {sample }}$ is the absorbance of the test compound. EDTA was used as a standard.

Evaluation of antioxidant capacity by phosphomolybdenum method: The total antioxidant capacity of coriander seed extracts was evaluated by the method of Prieto et al. ${ }^{18}$. An aliquot of $0.1 \mathrm{~mL}$ of sample solution $(1 \mathrm{mg} / \mathrm{mL})$ was combined with $1 \mathrm{~mL}$ of reagent solution $(0.6 \mathrm{M}$ sulfuric acid, $28 \mathrm{mM}$ sodium phosphate and $4 \mathrm{mM}$ ammonium molybdate). The tubes were capped and incubated in a boiling water bath at $95{ }^{\circ} \mathrm{C}$ for $90 \mathrm{~min}$. After the samples had cooled to room temperature, the absorbance of the aqueous solution of each was measured at $695 \mathrm{~nm}$ against blank. A typical blank solution contained $1 \mathrm{~mL}$ of reagent solution and the appropriate volume of the same solvent used for the sample and it was incubated under same conditions as the rest of the sample. For samples of unknown composition, water soluble antioxidant capacity was expressed as equivalents of $\alpha$-tocopherol ( $\mathrm{mg} / \mathrm{g}$ of extract).

\section{RESULTS AND DISCUSSION}

Flavonols, hydroxybenzoic acid and hydroxycinnamic acid present in spices, herbs and vegetables have been considered a therapeutic agent due to their beneficial health effects, such as their supposed protection against certain cancers, cardiovascular diseases and aging ${ }^{19}$. Moreover, these compounds have also been used as a source of colors for food products, mainly anthocyanins, in alternative to synthetic dyes whose harmful effects upon human health have often been assumed and, in some cases demonstrated. Therefore qualitative and quantitative analysis of the coriander seed extract was made using Ultra high performance liquid chromatography (UHPLC) as described in the experimental part and the results are presented in Table-1. The phenolic compounds in the coriander seed extract were identified by comparisons to the retention time and UV spectra of authentic standards while the quantitative data were calculated from the calibration curves. Salicylic acid was the dominant phenolic compound in coriander seed extract; it constituted about $650.80 \mu \mathrm{g} / \mathrm{g}$, followed by gentisic acid $(223.45 \mu \mathrm{g} / \mathrm{g})$, chlorogenic acid $(162.10 \mu \mathrm{g} / \mathrm{g})$, pyrogallol $(138.80 \mu \mathrm{g} / \mathrm{g})$ and syringic acid $(90.95 \mu \mathrm{g} / \mathrm{g})$. The three flavonols identified in the analysis were myricetin, quercetin and kaempferol. Quercetin was the most dominant flavonols in the coriander seeds studied as it accounted for the largest proportion of the total flavonols content (Table-1). In the hydroxycinnamic acid group, chlorogenic acid was the most dominant hydroxycinnamic acid followed by $p$-coumaric acid and ferulic acid. Salicylic acid was the dominant compound in the hydroxybenzoic acid group followed by gentisic acid, syringic acid and gallic acid. Previous work has established that the antioxidant properties of some plants are partly due to low molecular mass phenolic compounds, particularly flavonoids, which are known to be potent antioxidants ${ }^{20}$. The results suggest that flavonols like myricetin, quercetin, together with hydroxybenzoic acid, hydroxycinnamic acid and other group of phenolic acids play a predominant role in the seeds of coriander. In humans, the presence of flavonoids may contribute to the neutralization of cell-damaging free radicals and the maintenance of heart health ${ }^{19}$. The presence of hydroxycinnamic and hydroxybenzoic acids in our diets may also contribute to bolster cellular antioxidant defenses and to maintain a healthy vision. Although flavonoids are increasingly recognized as playing important roles as antioxidant. Further work is necessary to uncover the full potential of these compounds in the improvement of human health.

Total phenolic and flavonoid content: The total phenolic content of the extracts from seeds of $C$. sativum was determined by FC method and the results are expressed as equivalents of gallic acid (Table-2). Among the four extracts, ethyl acetate extract had the highest $(23.09 \mathrm{mg} / \mathrm{g}$ ) amount of phenolic compounds followed by butanol $(21.95 \mathrm{mg} / \mathrm{g})$, methanol $(8.77$ $\mathrm{mg} / \mathrm{g})$ and water extract $(8.23 \mathrm{mg} / \mathrm{g})$. Wangensteen et al..$^{10}$, also reported that ethyl acetate extract had the highest content of phenolic compounds in the coriander from Norway. The total flavonoid content varied from 0.26 to $1.08 \mathrm{mg}$ quercetin/ $\mathrm{g}$ weight (Table-2). The levels of total phenolics determined in this way are not absolute measurements of the amounts of phenolic compounds, but are in fact based on their chemical 
TABLE-1

MAJOR PHENOLIC COMPOUNDS IDENTIFIED IN THE Coriandrum sativum SEED EXTRACT BY UHPLC

\begin{tabular}{lc}
\hline \multicolumn{1}{c}{ Compounds } & Concentration $(\mu \mathrm{g} / \mathrm{g})$ \\
\hline Flavonols & $39.75 \pm 0.070$ \\
Myricetin & $56.40 \pm 0.141$ \\
Quercetin & $10.85 \pm 0.353$ \\
Kaempferol & \\
Hydroxycinnamic acid & $162.10 \pm 1.131$ \\
Chlorogenic acid & $31.15 \pm 0.353$ \\
p-Coumaric acid & $28.80 \pm 0.141$ \\
Ferulic acid & $0.95 \pm 0.212$ \\
$m$-Coumaric acid & $21.35 \pm 0.070$ \\
$o$-Coumaric acid & \\
Hydroxybenzoic acid & $59.10 \pm 0.282$ \\
Gallic acid & $49.65 \pm 0.070$ \\
Protocatechuic acid & $38.25 \pm 0.636$ \\
$\beta$-Resorcylic acid & $51.90 \pm 0.282$ \\
Vanillic acid & $650.80 \pm 21.49$ \\
Salicylic acid & $223.45 \pm 8.890$ \\
Gentisic acid & $90.95 \pm 0.636$ \\
Syringic acid & \\
Other phenolic compounds & $138.80 \pm 1.555$ \\
Pyrogallol & $68.80 \pm 0.989$ \\
Veratric acid & $73.65 \pm 3.040$ \\
Rutin & $32.45 \pm 0.494$ \\
Vanillin & $23.70 \pm 4.666$ \\
Hesperidin & $31.15 \pm 0.353$ \\
Resveratrol & $15.80 \pm 0.848$ \\
Naringenin & $22.55 \pm 0.070$ \\
Formononetin & $13.35 \pm 0.212$ \\
Biochanin A & \\
\hline Values are means of triplicates $\pm \mathrm{SD}$ & \\
\hline &
\end{tabular}

TABLE-2

TOTAL PHENOLIC (EXPRESSED AS GALLIC ACID EQUIVALENTS) AND FLAVONOID CONTENT (EXPRESSED AS MG QUERCETIN/G) FROM SEED EXTRACTS OF Coriandrum sativum

\begin{tabular}{lcc}
\hline \multicolumn{1}{c}{ Extract } & $\begin{array}{c}\text { Total phenolic content } \\
(\mathrm{mg} / \mathrm{g})\end{array}$ & $\begin{array}{c}\text { Total flavonoid } \\
\text { content }(\mathrm{mg} / \mathrm{g})\end{array}$ \\
\hline Ethyl acetate & $23.09 \pm 1.26$ & $1.08 \pm 0.12$ \\
Methanol & $8.77 \pm 0.27$ & $0.59 \pm 0.07$ \\
Butanol & $21.95 \pm 0.95$ & $0.43 \pm 0.01$ \\
Water & $8.23 \pm 0.58$ & $0.26 \pm 0.07$ \\
\hline \multicolumn{2}{l}{ Values are means of triplicates $\pm \mathrm{SD}$}
\end{tabular}

reducing capacity relative to gallic acid ${ }^{5}$. The phenolic compounds are the dominant antioxidants that exhibit scavenging efficiency on free radicals and reactive oxygen species are numerous and widely distributed in the plant kingdom ${ }^{19}$.

DPPH-radical scavenging activity: The free radical scavenging activity of the extracts was tested through DPPH method ${ }^{15}$ and the results were compared with BHT (Fig. 1). DPPH is usually used as a substrate to evaluate antioxidative activity of antioxidants. The method is based on the reduction of methanolic DPPH-solution in the presence of a hydrogen donating antioxidant, due to the formation of the non-radical form DPPH-H by the reaction. The coriander seed extracts were able to reduce the stable radical DPPH- to the yellow colored diphenylpicrylhydrazine. The $\mathrm{IC}_{50}$ values of the extracts were ethyl acetate $(37.57 \mu \mathrm{g} / \mathrm{mL})$, butanol $(46.87 \mu \mathrm{g} /$ $\mathrm{mL})$, methanol $(69.45 \mu \mathrm{g} / \mathrm{mL})$ and water $(73.24 \mu \mathrm{g} / \mathrm{mL})$ respectively. Wangensteen et al ${ }^{10}$ also reported that ethyl acetate fraction exhibited highest antioxidant activity when compared with other solvent extracts $\left(\mathrm{EtOH}, \mathrm{CH}_{2} \mathrm{Cl}_{2}, \mathrm{BuOH}\right.$ and $\mathrm{H}_{2} \mathrm{O}$ ). It has been found that cysteine, glutathione, ascorbic acid, tocopherol, polyhydroxy aromatic compounds (e.g., hydroquinone, pyrogallol, gallic acid) and aromatic amines (e.g., $p$-phenylene diamine, $p$-aminophenol), reduce and decolorize 1,1-diphenyl-2-picrylhydrazyl by their hydrogen donating ability ${ }^{21,22}$. The positive correlation between polyphenolic content of the extracts and its antioxidant activity is well documented ${ }^{23}$. Therefore, the content of total phenolic compounds in the extracts might explain their high antioxidant activities. In this study, the extracts exhibited a concentration dependent antiradical activity by inhibiting DPPH-radical (Fig. 1). Of the different extracts, ethyl acetate extract exhibited the highest antioxidant activity of $93.62 \%$ at $100 \mu \mathrm{g} / \mathrm{mL}$ concentration, followed by butanol ( $78.82 \%)$, water $(69.65 \%)$ and methanol $(63.02 \%)$, respectively at the same concentration and it indicates that compounds with strong radical-scavenging capacity are of medium polarity (Fig. 1). One of the possible mechanisms is polyphenolic associated compounds. Those kinds of phenolic compounds show antioxidant activity due to their redox properties, which play an important role in absorbing and neutralizing free radical, quenching singlet and triple oxygen or decomposing peroxide. Butylated hydroxytoluene (BHT) showed higher degree of free radical scavenging activity than that of the extracts at low concentration points. The DPPH activity of BHT exhibited $92.04 \%$ at $50 \mu \mathrm{g} / \mathrm{mL}$ concentration.

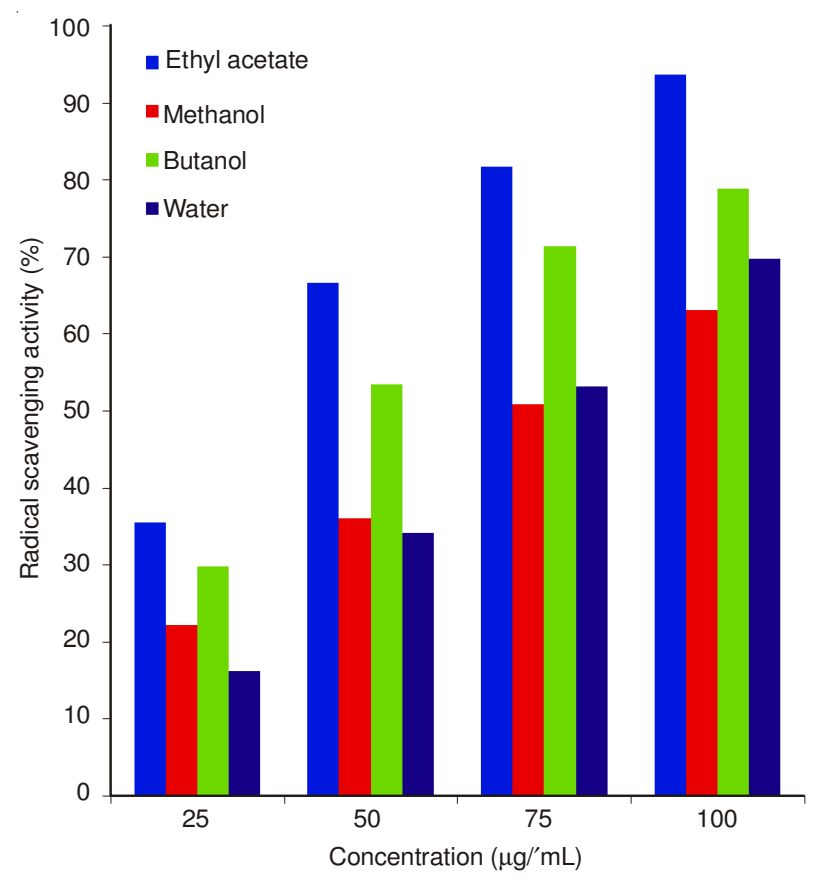

Fig. 1. Free radical-scavenging activity of the seed extracts from $C$. sativum at different concentrations by DPPH method. Each sample was assayed in triplicate for each concentration. Experimental results were means $\pm \mathrm{SD}$ of three parallel measurements

Assay of reductive potential: Various mechanisms, including reducing capacity, prevention of chain initiation, binding of transition metal ion catalysts, decomposition of peroxides, prevention of continued hydrogen abstraction and radical scavenging have been claimed to explain the antioxidant 
activities ${ }^{24}$. The reducing capacity of a compound may serve as a significant indicator of its potential antioxidant activity. In the present study, the extracts exhibited effective reducing capacity at all concentration points. The reducing capacity of the extracts increased with increase in the concentration (Fig. 2). The reducing power of the extracts followed the order of ethyl acetate extract $>$ butanol extract $>$ water $>$ methanol extract. The reducing properties are generally associated with the presence of reductones, which have been shown to exert antioxidant action by breaking the free radical chain, by donating a hydrogen atom ${ }^{25}$. Reductones are also reported to react with certain precursors of peroxide, thus preventing peroxide formation. Our data on the reducing capacity of extracts suggested that reductone-associated and hydroxide groups of compounds can act as electron donors and can react with free radicals to convert them to more stable products and thereby terminate radical chain reactions.

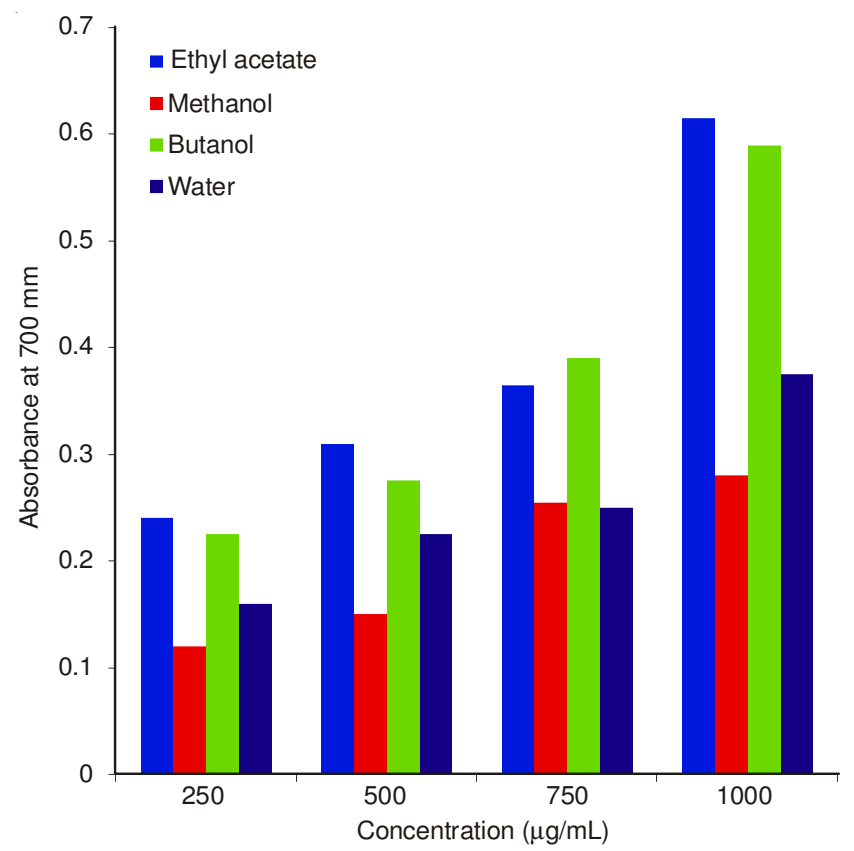

Fig. 2. Reducing power of the extracts from $C$. sativum seeds at different concentrations. Each sample was assayed in triplicate for each concentration. Experimental results were means $\pm \mathrm{SD}$ of three parallel measurements

Metal chelating activity: Ferrozine can quantitatively form complexes with $\mathrm{Fe}^{2+}$. In the presence of chelating agents, the complex formation is disrupted, resulting in a decrease in the red color of the complex. Measurement of color reduction therefore allows estimating the metal chelating activity of the coexisting chelator ${ }^{26}$. It is reported that chelating agents which form $\sigma$-bonds with metal, are effective as secondary antioxidants because they reduce the redox potential, thereby stabilizing the oxidized form of the metal ion $^{27}$. In this assay, both the extracts and standard compounds interfered with the formation of ferrous complex with the reagent ferrozine, suggesting that it has potential chelating activity and captures the ferrous ion before ferrozine. The absorbance of $\mathrm{Fe}^{2+}$ ferrozine complex is linearly decreased with dose taken (50 to $250 \mu \mathrm{g} / \mathrm{mL}$ ). The percentages of metal chelating capacity at $250 \mu \mathrm{g} / \mathrm{mL}$ doses of the extracts were found to be ethyl acetate $(81.27 \%)$, butanol $(77.91 \%)$ water $(68.65 \%)$ and methanol (68.44\%), respectively (Fig. 3). The standard EDTA exhibited $98.59 \%$ activity at $100 \mu \mathrm{g} / \mathrm{mL}$ concentration. The data obtained reveals that the extracts demonstrate an effective capacity for iron binding, suggesting that its action as antioxidant may be related to its iron-binding capacity.

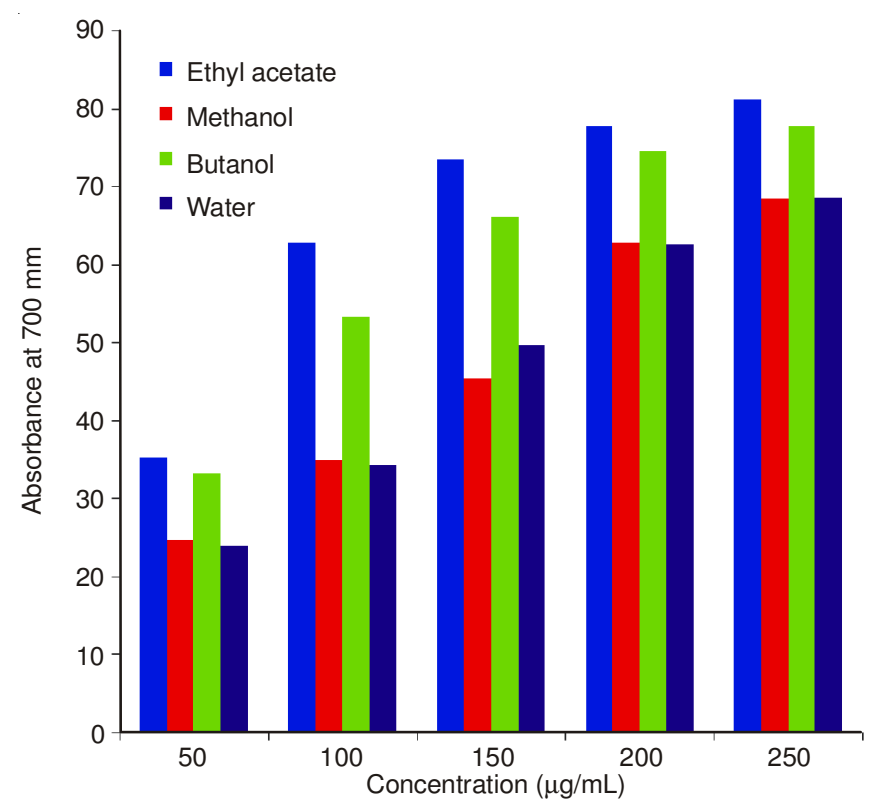

Fig. 3. Metal ion chelating effect of the extracts from $C$. sativum seeds. Each sample was assayed in triplicate for each concentration. Experimental results were means \pm SD of three parallel measurements

Evaluation of antioxidant capacity by phosphomolybdenum method: The antioxidant capacity of the coriander seed extracts was measured spectrophotometrically through phosphomolybdenum method, which is based on the reduction of $\mathrm{Mo}(\mathrm{VI})$ to $\mathrm{Mo}(\mathrm{V})$ by the sample analyte and the subsequent formation of green phosphate/Mo(V) compounds with a maximum absorption at $695 \mathrm{~nm}$. The antioxidant capacity of the extracts was found to decrease in the order: ethyl acetate extract $>$ butanol extract $>$ water $>$ methanol extract (Table-3).

\begin{tabular}{lc}
\multicolumn{2}{c}{ TABLE-3 } \\
ANTIOXIDANT CAPACITY OF Coriandrum sativum SEED \\
\multicolumn{2}{c}{ EXTRACTS BY PHOSPHOMOLYBDENUM METHOD } \\
\hline \multicolumn{1}{c}{ Extract } & $\begin{array}{c}\text { Antioxidant capacity [as equivalent to } \\
\text { a-tocopherol }(\mathrm{mg} / \mathrm{g})]\end{array}$ \\
\hline Ethyl acetate & $47.50 \pm 2.23$ \\
Methanol & $73.01 \pm 3.44$ \\
Butanol & $74.29 \pm 2.70$ \\
Water & $75.25 \pm 4.73$ \\
\hline Values are means of triplicates \pm SD
\end{tabular}

\section{Conclusion}

In our present study, polyphenolic composition and antioxidant activity of the coriander seed cultivated in Korea were analyzed. UHPLC analysis of the coriander seed extract revealed that salicylic acid was the dominant phenolic compound followed by gentisic acid, chlorogenic acid, pyrogallol and syringic acid. The decreasing order of antioxidant activity among the coriander seed extracts assayed through all the four 
methods was found to be ethyl acetate extract $>$ butanol extract $>$ methanol extract $>$ water. This order is similar to the phenolic contents of the extracts that showed the extent of antioxidant activity is in accordance with the amount of phenolics present in that extract. The knowledge of the phenolic profile, occurring in the coriander seeds holds great significance from both dietary and nutritional point of view. Our results indicate that inclusion of coriander seeds in the cuisine will increase the content of antioxidants and thus probably prevent oxidative deterioration of food.

\section{ACKNOWLEDGEMENTS}

One of the authors, Praveen Nagella is recipient of the Konkuk University SMART Research Professor Program, Konkuk University, Seoul, South Korea.

\section{REFERENCES}

1. M.H. Eikani, F. Golmohammad and S. Rowshanzamir, J. Food Eng., 80, 735 (2007).

2. M. Emamghoreishi, M. Khasaki and M.F. Aazam, J. Ethnopharmacol., 96, 365 (2005).

3. K. Msaada, K. Hosni, M.B. Taarit, T. Chahed, M.E. Kchouk and B. Marzouk, Food Chem., 102, 1131 (2007).

4. C. Kaur and H.C. Kapoor, Int. J. Food Sci. Technol., 36, 703 (2001).

5. J.G. Elliot, Food Technol., 53, 46 (1999).

6. Y. Choi and J. Lee, Food Chem., 114, 1386 (2009).

7. I.S. Carvalho, T. Cavaco and M. Brodelius, Ind. Crops Prod., 33, 382 (2011).
8. R.J. Nijveldt, E. van Nood, D.E.C. van Hoorn, P.G. Boelens, K. van Norren and P.A.M. van Leeuwen, Am. J. Clin. Nutr., 74, 418 (2001).

9. V. Katalinic, S.S. Mozina, D. Skroza, I. Generalic, H. Abramovic, M. Milos, I. Ljubenkov, S. Piskernik, I. Pezo and P. Terpinc, Food Chem., 119, 715 (2010).

10. H. Wangensteen, A.B. Samuelsen and K.E. Malterud, Food Chem., 88, 293 (2004)

11. N.B. Guerra, E. de Almeida Melo and J.M. Filho, J. Food Compos. Anal., 18, 193 (2005)

12. G. Singh, S. Maurya, M.P. de Lampasona and C.A.N. Catalan, Flavour Fragrance J., 21, 472 (2006).

13. V.L. Singleton and J.A. Rossi, Am. J. Enol. Vitic., 37, 144 (1965).

14. W.C. Willett, Science, 296, 695 (2002).

15. D.R. Katerere and J.N. Eloff, Phytother. Res., 19, 779 (2005).

16. M. Oyaizu, Jpn. J. Nutr., 44, 307 (1986).

17. T.C.P. Dinis, V.M.C. Madeira and L.M. Almeida, Arch. Biochem. Biophys., 315, 161 (1994).

18. P. Prieto, M. Pineda and M. Aguilar, Anal. Biochem., 269, 337 (1999).

19. R.L. Prior and G. Cao, Hortic. Sci., 35, 588 (2000).

20. J.A. Ross and C.M. Kasum, Annu. Rev. Nutr., 22, 19 (2002).

21. H. Wang, M.G. Nair, G.M. Strasburg, A.M. Booren and J.I. Gray, J. Agric. Food Chem., 47, 840 (1999).

22. M.S. Blois, Nature, 181, 1199 (1958)

23. S.J. Huang and J.L. Mau, LWT-Food Sci Technol., 39, 707 (2006).

24. R. Re, N. Pellegrini, A. Proteggente, A. Pannala, M. Yang and C. RiceEvans, Free Radic. Biol. Med., 26, 1231 (1999).

25. P.-D. Duh, J. Am. Oil Chem. Soc., 75, 455 (1998).

26. F. Yamaguchi, M. Saito, T. Ariga, Y. Yoshimura and H. Nakazawa, J. Agric. Food Chem., 48, 2320 (2000).

27. E. Keowmaneechai and D.J. McClements, Food Res. Int., 39, 230 (2006). 